\title{
Opening the black-box - an observational study of teaching and learning interactions for paediatrics trainees on consultant ward rounds.
}

Type of article: Original article

Authors

Dr Amy Gray $(1,2,3)$

Ms Helen Enright (1)

1. Department of Paediatrics, The University of Melbourne, Parkville, Victoria 3052

2. The Royal Children's Hospital, Parkville, Victoria, 3052

3. Murdoch Childrens Research Institute, Parkville, Victoria, 3052

Corresponding author

Dr Amy Gray

Level 2, Academic Centre, Royal Children's Hospital

50 Flemington Rd, Parkville, Victoria 3052

Email:amy.gray@rch.org.au

Phone: +61393454647

\section{Acknowledgements}

This work was possible due to funding from the Royal Children's Hospital Foundation, under the Enhancing Education Grant whom we thank for their support. We wish to acknowledge the consultants and trainees in the Department of General Medicine who enabled this research to happen through opening their ward rounds to us.

This is the author manuscript accepted for publication and has undergone full peer review but has not been through the copyediting, typesetting, pagination and proofreading process, which may lead to differences between this version and the Version of Record. Please cite this article as doi: 10.1111/jpc.14056

This article is protected by copyright. All rights reserved. 


\title{
Opening the black-box - an observational study of teaching and learning interactions for paediatrics trainees on consultant ward rounds.
}

\author{
Abstract \\ Introduction \\ Ward rounds are complex activities in which education must be balanced against \\ service. Limited evidence exists regarding how to optimise ward round education. In \\ order to improve the educational experience, we aimed to understand the teaching and \\ learning interactions on ward rounds with a particular focus on the experience of \\ paediatric trainees. \\ Methods
}

We conducted an initial quantitative survey as a needs assessment regarding learning and teaching in clinical settings using a structured survey of 21 trainees. This was followed by an observational study using focused ethnography of 20 consultant ward rounds in a general medical department of tertiary paediatric hospital. We used a structured observation form to document ward round characteristics and educational interactions. Data were analysed using inductive content analysis to understand key influences on teaching and learning interactions.

Results

Trainees reported a discrepancy between the actual educational value of ward rounds (mean rating 2.7/5) and what they desired (mean 4.3/5). Ward round ethnography revealed examples of excellent education and practice alongside missed opportunities. Explicit education on rounds was dominated by technical content with little focus on other aspects of professionalism. Major influences on educational interactions were the ward round model - consultant-as-expert vs learner-centred - and the hidden curriculum.

Conclusion 
There are many examples of excellence in ward round education, yet there remains substantial scope to better harness the education potential of rounds. This requires us to challenge assumptions, enable feedback and reflection and make learning explicit while putting the learner at the centre of educational opportunities.

\section{Key words}

Paediatric, Consultants, Education, Focused Ethnography, Ward rounds.

\section{Learning points}

What is already known on this topic:

- Ward rounds are complex activities in increasingly busy clinical environments, and education is traditionally a part of this.

- Education on rounds is often guided by historical practices rather than evidence regarding how we teach and learn.

What this paper adds:

- Our study demonstrates a discrepancy between the desired and actual educational value of ward rounds for trainees in our setting.

- Whilst there are examples of excellence in clinical practice and education on ward rounds, there are missed opportunities for teaching and learning in areas such as communication, uncertainty and professionalism.

- Key influences on ward round education are the ward round model - whether consultant-centric or learner-centric - and the hidden curriculum.

This article is protected by copyright. All rights reserved. 
Understanding educational potential of paediatric ward rounds

\section{Introduction}

Ward rounds are a fundamental aspect of hospital care with a primary focus on assessing patients, their progress, making treatment decisions and communicating these to patients and families. While the concept of ward rounds is immediately familiar, individual ward rounds are a relative "black box". (1) What occurs within them reflects great variation in consultant practices, attitudes towards care and education, time pressures and expectations.(2) They are complex activities with increasing competing pressures including patient load, critical or complex illness and access to beds.(3) While there is a long tradition of educating medical students and training doctors on ward rounds, there is increasing tension between education and service delivery. $(3,4,5)$

In available literature on the educational value of rounds trainees report mixed but often relatively negative views. There is evidence of poor learning recall, a paucity of opportunities to learn specific skills such as physical examination or history taking, and little feedback.(6, 9-11) These views are often at odds with consultants or supervisors. $(12,13)$ Negative perceptions may result from the fact there is much opportunity from learning on the job, but the learning itself can be implicit, unsystematic and opportunistic. (2). System issues such as restricted working hours have also had a large impact, with rounds occupying proportionally more of working hours with relatively less time for teaching. $(4,5)$

But, if we ultimately believe that education should retain a key place on rounds then we need to understand how it could be optimised given the challenges of clinical medicine.(2, 6-8) Recent observational evidence linked higher learner satisfaction on rounds with three teaching activities; patient care-related questions, real-time feedback and learner-driven topics.(14) A review of ward round literature found agreement regarding the need to consciously structure rounds to maximise learning.(6) Other authors have used theory to develop questions to plan teaching on round (15) and developed and validated checklists for ward round performance.(16) 
We aimed to understand the perceived educational value of ward rounds for paediatric trainees, and the teaching and learning interactions which were occurring on rounds. In doing this we hoped to understand how we might intervene to improve their educational value.

\section{Methods}

\section{$\underline{\text { Setting }}$}

Our study was conducted in the general medical department of a quaternary level paediatric hospital. The department comprises inpatient teams to which one paediatric registrar (PGY3 or above), one junior medical officer (usually PGY2) and up to four medical students are allocated at one time.

\section{$\underline{\text { Study design }}$}

We conducted an initial needs assessment of clinical education activities using a structured survey sent to all trainees working in the department during a 3 month rotation. Participants were asked to rate the educational value of clinical activities, both desired and actual, on a 5-point Likert scale and the frequency of learning/teaching methods they experienced on a 4-point scale from 1(rarely) to 4(often).

From the survey results we identified the need to understand the teaching and learning occurring on ward rounds, which we undertook through a qualitative study using focused ethnography. 17) Ward rounds have strong traditions attached to them and, at their core, are social interactions which ethnography can elucidate.(18) Focused ethnography describes the experience of a particular issue (teaching and learning) within a particular context (the ward round).(19)

Two researchers observed 30 consultant ward rounds over a 3 month period. One researcher was a clinician from the department with medical education expertise (providing an insider perspective) whilst the second researcher was an educationalist 
(providing an outsider perspective). Observations were conducted over summer when the clinical burden on the department was lowest, with fewer medical students. This was an ideal opportunity to analyse education of training doctors.

Ward consultants were informed of the study and ward round observations in face-toface meetings. Consultants were approached by email to request that an observer attend their ward round at least 24 hours prior. They were able to accept, decline or propose an alternate day for observation. All consultants were offered an opportunity to meet with the observer after the round to reflect on events.

A structured observation form was used to record details relating to the duration of the round, number of patients seen, ward round structure, teaching methodologies observed and teaching content. Post-round discussions with staff occurred after two thirds of observed rounds and provided extra subjective data. Data from observations and accompanying field notes were transcribed and then analysed using inductive content analysis to identify key features of teaching and learning encounters on rounds. This method of analysis was chosen as we did not wish to make assumptions about teaching and learning we might see, but to draw themes from our observations. Transcripts were reviewed, codes identified and themes created in an iterative process by the two researchers.

Approval for the research was obtained from the Human Research Ethics Committee at the Royal Children's Hospital (HREC 36213A).

\section{Results}

Twenty-one junior medical staff (response rate 100\%) responded to the survey. There was a discrepancy between the educational value desired by trainees from ward rounds, compared to the actual value received. (Figure 1) Trainees perceived the most common learning and teaching methods were observation only and asking questions, whilst feedback was uncommon. (Figure 2) 
Understanding educational potential of paediatric ward rounds

Our qualitative data identified three key factors influencing teaching and learning interactions on ward rounds.

\section{Consultant-as-expert rounds}

The predominant model of ward rounds was the consultant-as-expert, reflecting a traditional apprenticeship-style approach. The person leading patient encounters was usually assumed, rather than explicitly discussed. Most commonly it was the consultant who also physically led into the room. Medical team members were often not introduced to families individually. Sometimes teams had met the patient previously and it was assumed families remembered them. In other instances this was the first meeting and most commonly, a general introduction was made - "we are the medical team”.

Overall this model was characterised by closed or limited questioning of trainees. When open questions were asked and the trainee could not answer, they were often quickly followed by closed questioning, statements or "mini-lectures", rather than reframing questions.

Consultant: "How do you think about the immune system, in broad terms?"

$$
\begin{gathered}
\text { PGY2: "I am not sure I understand the question?" } \\
\text { Consultant: "I like to think of it in terms of the cell types and what } \\
\text { they do...(proceeding to explanation)" }
\end{gathered}
$$

The focus of education was predominantly clinical content including factual recall. Communication, clinical uncertainty, decision-making, professional interactions and quality and safety however were fundamental to every round, with many examples of excellence in these domains from both consultants and trainees. However, these skills were rarely made explicit, nor the focus of reflection or feedback. When this phenomenon was raised with consultants in post-round discussions the most common 
Understanding educational potential of paediatric ward rounds

response was the difficultly reflecting on your own communication or performance without the appearance of "bragging".

Consultant-led teaching strategies to make learning explicit included sign-posting key aspects of patient care. Examples included highlighting "the traps" in patient management, "the key here..." when talking to patients and junior medical staff about the management of a child, and raising "red flags" in certain clinical circumstances. In addition several consultants were adept at articulating their clinical reasoning and decision-making processes, thereby making them visible to trainees.

\section{$\underline{\text { Learner-centred rounds }}$}

Learner-centred ward rounds, whilst uncommon, were an alternate model of ward round. These were characterised by encouragement of training doctors to lead encounters, and in some instances expectation that this role would be rotated among all team members. Questioning tended to be open-ended, with probing or reframing questions to explore the learner's understanding beyond their first response. Where possible different questions were addressed to learners of different levels, or peerlearning was encouraged. These encounters emphasized the value of all team members and were less hierarchical.

\section{Consultant to PGY1: "Do you remember what causes poor feeding?" (PGY1 responds) \\ Consultant to PGY2: "Shall we phone a friend? Can you help fill in gaps? \\ (PGY2 responds) \\ Consultant to PGY3: "is there anything else you would consider?"}

Beyond time pressures, learner-led education was challenged by the ward round circumstances. On a number of occasions when trainees took the lead they were interrupted by phones or pagers, requiring the consultant to step in. Learner-led education was also challenged by uncertainty, both in decision-making and in 
Understanding educational potential of paediatric ward rounds

understanding whether there was "permission to proceed". This was exemplified by junior medical staff discussing a management plan with a family, encountering a dilemma about the answer to provide, and seeking affirmation from consultants, usually through non-verbal cues. The ability of the consultant to recognise and intervene when this occurred was fundamental to junior staff resolving this conflict and progressing the encounter.

One strategy was to pause the clinical encounter to facilitate explicit decision-making before finishing the discussion with either staff or patients.

$$
\begin{aligned}
& \text { Consultant: "If you were the boss what would you do?" } \\
& \text { PGY3: "I'd stop the ..." } \\
& \text { Consultant: "Ok we'll talk to ICU about that." } \\
& \text { Consultant to nurse: "Ok our preference is to stop ..." }
\end{aligned}
$$

Alternatively, the consultant could intervene to provide clarity to an explanation, agreement or additions to a plan, or enable the team to exit the encounter to discuss issues away from the bedside.

\section{Consultant: " $\operatorname{Dr} X(P G Y 3)$ and I will have a think about that and get back to you with our plan.'}

In both cases, the consultant has an opportunity to provide clarity for learning, but also validate the training doctor's expertise and role in the team.

\section{$\underline{\text { Hidden curriculum }}$}

The clinical focus of explicit education in a consultant-as-expert ward round is part of a hidden curriculum emphasizing knowledge over the other skills such as communication or uncertainty. The role of hierarchy and the established practice that the consultant leads into a patient's room is another example. This extended to trainees opening the door and waiting for the paediatrician researcher conducting observations for this study to enter the room first. 
The structure of the ward round is often assumed and rarely made explicit, to both staff and patients. For patients and families, there is an assumption that they understand the purpose of the round, and when and how doctors will see them every day. Ward rounds frequently began with the consultant being led to the first patient and ended when the last patient was seen. Overall, there were few opportunities for planning what would be achieved on the round, or providing closure at the end for clinical issues or learning.

There were several occasions where reference was made to our presence on rounds observing education and the consultant would provide an "example" of education for our benefit - in all instances in the form of didactic information-giving. This represents underlying assumptions about what constitutes education. Similarly staff questioned why we wanted to observe education on ward rounds in the absence of medical students. This perhaps implies for whom it is perceived education is intended and ignores the need to prioritise education for junior medical staff as part of their daily work.

\section{Discussion}

Teaching and learning on ward rounds is a complex activity which must be balanced against, or take a back seat to service. From our observations of rounds, there is a wealth of educational opportunities, but they are often implicit rather than explicit, particularly when the consultant takes the role of expert.(2) These opportunities may easily be missed by trainees dealing with the cognitive load of actively doing their job while trying to learn from the large amount of information exchanged. This may explain discrepancies between consultants and trainees perceptions of education on rounds, both in this and other contexts. $(6,12,13)$

When explicit education occurs it is often focused on clinical content and recall, rather than other domains of competence such as communication and uncertainty for which rich opportunities exist.(20) This potentially undermines the importance of skills such as communication, dealing with uncertainty, clinical reasoning, and situation 
management which may be viewed as "softer skills" if they are not given due emphasis by senior medical staff. This is problematic given the contribution these factors make towards problems arising in patient care.(21)

Explicit education on rounds is strongly linked to the presence of medical students in our context, a situation which belies its importance for training doctors. The potential consequence is for trainees to be pushed out of educational opportunities, when it is perhaps the key opportunity for consultants to observe their performance first hand. Literature tells us that specific and timely feedback is one of the most powerful tools for learning, yet our observations and evidence from ward rounds show how infrequently it occurs. $(8,22)$ Specific strategies are required to overcome the barriers to feedback in busy, complex clinical environments.

The traditional clinical model of consultant-as-expert is at odds with evidence telling us education should be learner-centred. Shifting this balance on rounds may have a number of advantages.(1, 3, 23) It could potentially move the emphasis on what is taught and learned from clinical recall to other domains of professional competence, and increase educational impact by incorporating opportunities for feedback or reflection. But there are challenges in doing this, including the comfort and capability of consultants, their perceived expertise in areas such as communication, potential discomfort of including feedback in ward round settings, and competing clinical demands.

A potential solution lies in deliberately structuring rounds to optimise education including setting a clear plan for the round which incorporates learners' needs, and ensuring a clear end which permits the team to pause to articulate both clinical plans and learning. $(2,3,8,13)$ Asking the team for reflections on patient encounters can extend learning beyond technical content. Effective questioning - "asking, rather than telling" - ensures content is relevant for the learner. Finally learning can be made explicit simply by naming it when it occurs. 
There are a number of limitations of our current study. Firstly, we have observed a limited number of ward rounds in one department and institution. Whilst this may limit our ability to generalise the issues raised, many are reflected in existing ward round literature and do not appear to be isolated phenomenon. Secondly, staff were aware of our observations and this may have led to a Hawthorne effect and better education delivery - that is, a best case scenario. If that is the case, there is still large gap in ideal versus current practice which can be addressed. Moreover references made by participants during our observations regarding the impact of being observed highlighted their biases towards didactic education over alternative methods of teaching and learning. Finally, the findings reported in this study are the authors' perception of what were observed. However post-ward round discussions with consultants and subsequent presentations of our data to the department affirm this is likely an accurate representation, albeit a generalisation, of the predominant types of teaching and learning interactions which are occurring.

Ward rounds remain an important part of our medical culture yet, there is much opportunity to better harness their educational potential. If we believe in the educational value of rounds, we need to rethink long-held assumptions regarding rounds and find ways to add value, but not an additional time burden to already busy clinicians. 
Understanding educational potential of paediatric ward rounds

\section{References}

1. Bleakley A. Pre-registration house officers and ward-based learning: A 'new apprenticeship' model. Med Educ. 2002;36(1):9-15.

2. Stanley P. Structuring ward rounds for learning: can opportunities be created? Med Educ. 1998;32(3):239-43.

3. O'Hare JA. Anatomy of the ward round. Eur J Intern Med. 2008;19(5):309-13.

4. Ende J. What if Osler were one of us? Inpatient teaching today. J Gen Intern Med. 1997;12:S41-S8.

5. Stickrath C, Noble M, Prochazka A, Anderson M, Griffiths M, Manheim J, et al. Attending Rounds in the Current Era What Is and Is Not Happening. JAMA intern med. 2013;173(12):1084-9.

6. Laskaratos FM, Gkotsi D, Panteliou E, Epstein O. The educational value of ward rounds in conveying knowledge and developing trainees' clinical skills. Br J Hosp Med. 2014;75(3):162-5.

7. Reece A, Klaber R. Maximising learning on ward rounds. Arch Dis Child Educ Pract Ed. 2012;97(2):61-7.

8. Dewhurst G. Time for change: teaching and learning on busy post-take ward rounds. Clin Med. 2010;10(3):231-4.

9. Tariq M, Motiwala A, Ali SU, Riaz M, Awan S, Akhter J. The learners' perspective on internal medicine ward rounds: a cross-sectional study. BMC Med Educ. 2010;10:53

10. Elliot DL, Hickam DH. Attending rounds on inpatient units - differences between medical and nonmedical services. Med Educ. 1993;27(6):503-8.

11. Claridge A. What is the educational value of ward rounds? A learner and teacher perspective. Clin Med. 2011;11(6):558-62. 
Understanding educational potential of paediatric ward rounds

12. Gonzalo JD, Heist BS, Duffy BL, Dyrbye L, Fagan MJ, Ferenchick GS, et al. The Value of Bedside Rounds: A Multicenter Qualitative Study. Teach Learn Med. 2013;25(4):326-33.

13. Balmer DF, Master CL, Richards BF, Serwint JR, Giardino AP. An ethnographic study of attending rounds in general paediatrics: understanding the ritual. Med Educ. 2010;44(11):1105-16.

14. Merritt FW, Noble MN, Prochazka AV, Aagaard EM, Stickrath CR. Attending rounds: What do the all-star teachers do? Med Teach. 2017;39:100-104.

15. Ker J, Cantillon P, Ambrose L. Teaching on a ward round. BMJ 2008;337:a1930 16. Caldwell G, 2013. An evaluation of a formative assessment process used on post take ward rounds. Acute Med. 2013;12: 208-13.

17. Rashid M, Caine V, Goez H. The Encounters and Challenges of Ethnography as a Methodology in Health Research. Int J Qual Methods.2015;14.

18. Atkinson P, Pugsley L. Making sense of ethnography and medical education. Med Educ. 2005;39(2):228-34.

19. Venzon E, Higginbottom G. The use of focused ethnography in nursing research. Nurse Res. 2013;20(4):36-43.

20. Quilligan S. Learning clinical communication on ward-rounds: An ethnographic case study. Med teach. 2015;37(2):168-73.

21. Sutcliffe KM, Lewton E, Rosenthal MM. Communication failures: An insidious contributor to medical mishaps. Acad Med. 2004;79(2):186-94.

22. Laskaratos FM, Wallace D, Gkotsi D, Burns A, Epstein O. The educational value of ward rounds for junior trainees. Med Educ Online. 2015;20. 
Understanding educational potential of paediatric ward rounds

23. Ferenchick G, Simpson D, Blackman J, DaRosa D, Dunnington G. Strategies for efficient and effective teaching in the ambulatory care setting. Acad Med. 1997;72(4):277-80.

This article is protected by copyright. All rights reserved. 
Figure 1. The desired vs actual educational value of clinical activities as reported by trainees. Results are presented as the mean rating of trainees, based on a 5-point Likert scale.

Figure 2. The perceptions of trainees regarding the frequency with which they experience different learning and teaching methods on ward rounds. Results are presented as the percentage of trainees who perceive the learning/teaching method happening "sometimes" or "often". 


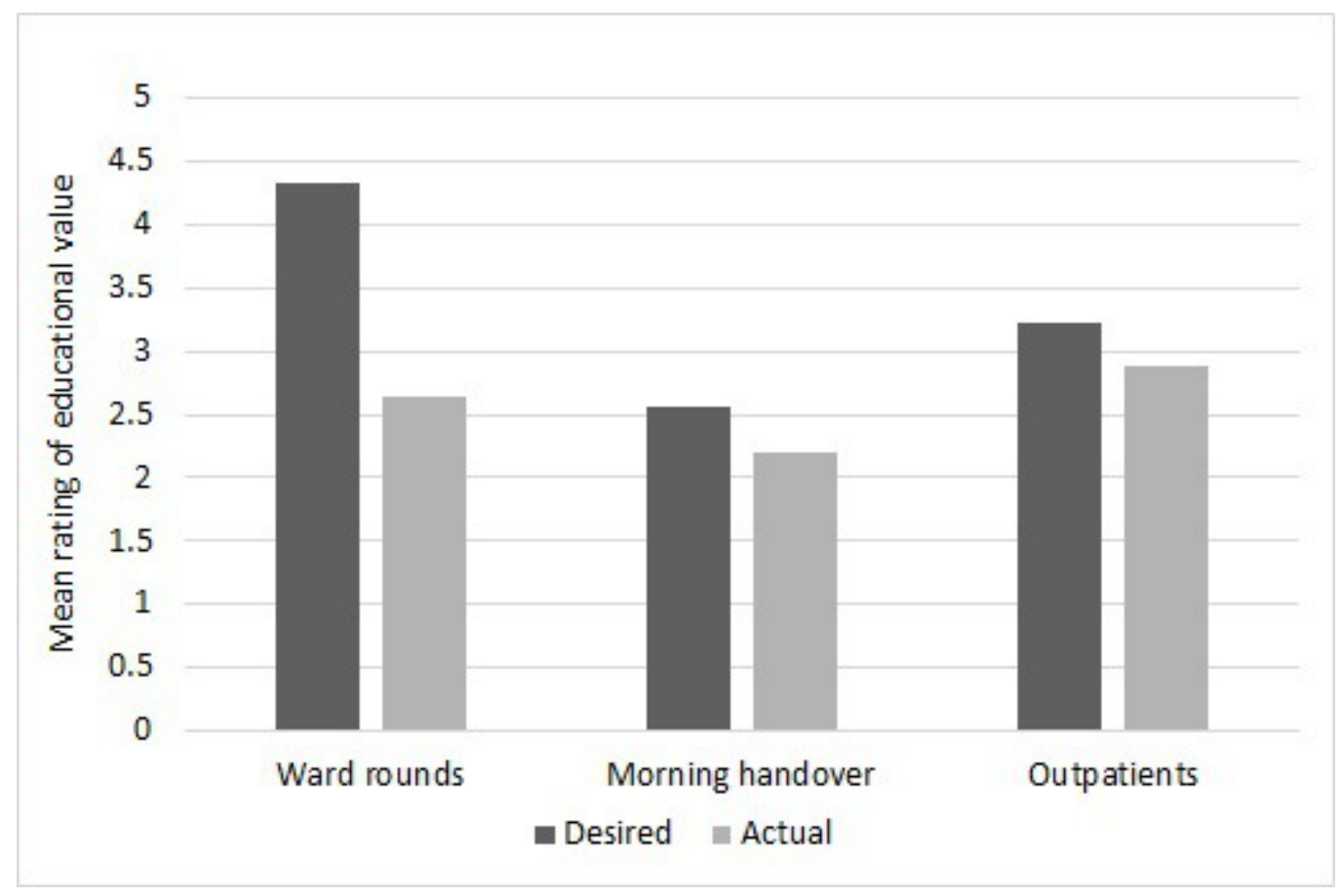

Figure 1.jpg

This article is protected by copyright. All rights reserved. 


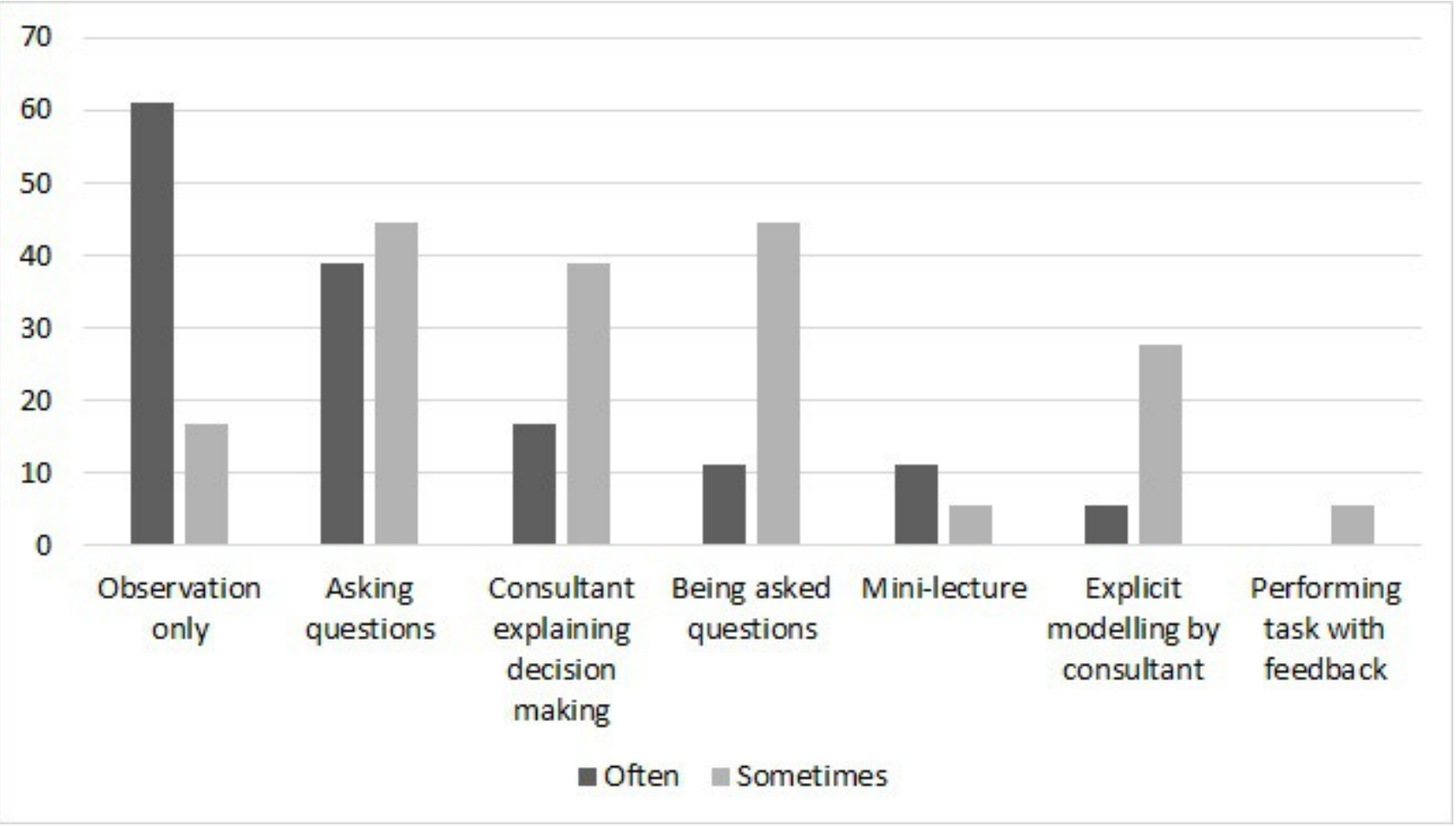

Figure 2.jpg

This article is protected by copyright. All rights reserved. 


\section{University Library}

\section{- M M N E R VA A gateway to Melbourne's research publications}

Minerva Access is the Institutional Repository of The University of Melbourne

Author/s:

Gray, A;Enright, $\mathrm{H}$

Title:

Opening the black box: An observational study of teaching and learning interactions for paediatrics trainees on consultant ward rounds

Date:

2018-09-01

\section{Citation:}

Gray, A. \& Enright, H. (2018). Opening the black box: An observational study of teaching and learning interactions for paediatrics trainees on consultant ward rounds. JOURNAL OF PAEDIATRICS AND CHILD HEALTH, 54 (9), pp.1011-1015. https://doi.org/10.1111/ jpc. 14056.

Persistent Link:

http://hdl.handle.net/11343/283986 